Original Article - Clinical Science

\title{
Incidence and correction of vision impairment among elderly population in southern urban China
}

\author{
Xiaotong Han PhD, ${ }^{1,2^{*}}$ Chimei Liao MD, ${ }^{1 *}$ Chi Liu MSc, ${ }^{3}$ Pei Ying Lee BOptom, ${ }^{2}$ Jian \\ Zhang $\mathrm{MS}^{1}$ Stuart Keel $\mathrm{PhD}^{2}$ and Mingguang He MD PhD ${ }^{1,2}$
}

* These two authors have made equal contributions

1. State Key Laboratory of Ophthalmology, Zhongshan Ophthalmic Center, Sun Yat-sen University, Guangzhou, China.

2. Centre for Eye Research Australia; Ophthalmology, Department of Surgery, University of Melbourne, Melbourne, Australia.

3. Guangzhou Healgoo Interactive Medical Technology Co. Ltd., Guangzhou, China.

Correspondence: Mingguang He, Department of Preventive Ophthalmology, Zhongshan Ophthalmic Center, Guangzhou 510060, China

Email: mingguang he@yahoo.com

Short running title: Incidence and correction of vision impairment Received 3 September 2018; accepted 22 October 2018

Funding sources: This work was supported by the Fundamental Research Funds of the State Key Laboratory in Ophthalmology, National Natural Science Foundation of China

This is the author manuscript accepted for publication and has undergone full peer review but has not been through the copyediting, typesetting, pagination and proofreading process, which may lead to differences between this version and the Version of Record. Please cite this article as doi: $10.1111 /$ ceo.13431

This article is protected by copyright. All rights reserved. 
[grant numbers 81125007], Science and Technology Planning Project of Guangdong Province, China [grant numbers 2013 B20400003].

Financial disclosure: Prof. He receives support from the University of Melbourne at Research Accelerator Program and the CERA Foundation. The Centre for Eye Research Australia receives Operational Infrastructure Support from the Victorian State Government. The sponsor or funding organization had no role in the design or conduct of this research.

Conflict of interest: None 


\section{ABSTRACT}

Importance: Data on the incidence of presenting vision impairment (PVI) and spectacle coverage rate (SCR) in urban China is limited.

Background: To estimate the 6-year incidence and risk factors for PVI and the SCR in urban Southern China.

Design: Population-based cohort study.

Participants: 1817 participants aged $\geq 35$ years were identified from Guangzhou in 2008 for baseline and 1427 attended follow-up examination in 2014.

Methods: Presenting VA (PVA) was measured using the ETDRS chart with habitual spectacles. Participants with PVA $\leq 20 / 40$ underwent subjective refraction at the followup visit. Incidence of PVI was calculated using the WHO and US criteria respectively. The met-need SCR was defined as the percentage of participants with PVA $<20 / 40$ that could be improved to $\geq 20 / 40$ after correction.

Main Outcome Measures: Incidence of PVI and SCR.

Results: Incidence of PVI was 8.3\% (95\%CI, 6.9-9.8) and 12.2\% (95\%CI, 10.5-14.0) based on the WHO and US definition, respectively. Older age, female, lower education level, more myopic spherical equivalent and worse PVA at baseline were significantly related to a higher PVI incidence based on the WHO criteria, with similar associations identified using the US criteria except for gender. The overall met-need SCR was $42.5 \%$, and it was lower among the elderly, more hyperopic participants, or participants with lower education level.

Conclusions and relevance: The incidence of PVI is high in urban Southern China and spectacle wearing is available in less than half of those in need. This highlights the needs to promote spectacle coverage even in the urban population. 
Key Words: incidence, vision impairment, presenting visual acuity, aging population, spectacle coverage, WHO, population-based study.

This article is protected by copyright. All rights reserved. 


\section{INTRODUCTION}

According to the 2017 World Health Organization (WHO) estimation, there were 253 million people with vision impairment (VI) and 36 million with blindness worldwide. ${ }^{[1]}$ Vision Impairment poses a substantial threat to quality of life by limiting functional and social life, as well as emotional well-being. ${ }^{[2-4]}$ With the ever-growing aging population, VI and blindness is projected to pose enormous social and economic burdens to the whole society, especially in developing and populous countries. ${ }^{[5,6]}$ Reported prevalence of VI in adults ranged from $2.9 \%$ to $15.8 \%$ in China. ${ }^{[7-9]}$ However, information on the incidence of VI in China, an essential knowledge for estimating the demand in the community in the perspective of future public health planning, is still limited. ${ }^{[8,10]}$

Given refractive error is the main cause of VI globally, appropriate spectacle correction is the most effective way to address this burden. ${ }^{[10-13]}$ Previous studies investigating the spectacle coverage rate (SCR) in China reported varying rates ranging from $44.1 \%$ to $71.2 \% \cdot{ }^{[14,15]}$ However, to date, there is a paucity of up-to-date data on the SCR in urban China, where $57 \%$ of the population resides. ${ }^{[16]}$ In addition, the global prevalence of myopia is increasing rapidly during the recent decades, especially in East and Southeast Asia. ${ }^{[17]}$ Reported myopia prevalence had exceeded $90 \%$ among teenagers in China. Thus, a better understanding of the current spectacles coverage rate (SCR) is clearly warranted to assist with planning of refractive service delivery and promoting eye care service uptake. 
We conducted a 6-year longitudinal, population-based study to investigate: (1) the incidence and risk factors of presenting VI (PVI); (2) the spectacle correction rate and performance in urban Southern China.

\section{METHODS}

\subsection{Study Population}

Participants aged 35 years or older were selected by random cluster sampling from the Yuexiu district of Guangzhou, China, which is a large urban area with an estimated population of 10.18 million. Demographic information including age, gender and educational level were documented at baseline in 2008. Details of the sampling and recruitment methodology have been described elsewhere. ${ }^{[18,19]}$ Briefly, 1817 of 2286 (79.5\%) eligible participants were enrolled at baseline and all were invited for a followup examination in 2014. Baseline and follow-up examinations were conducted using the same protocols at Zhongshan Ophthalmic Center (ZOC) or in local community facilities or homes for individuals with mobility restrictions or limited free time. Study protocols were approved by the World Health Organization Secretariat Committee on Research Involving Human Subjects and by the institutional review board at ZOC in Guangzhou, China. Written informed consent was obtained from all participants and the study was conducted in accordance with the tenets of the Declaration of Helsinki. The participants did not receive any financial compensation.

\subsection{Procedures}

Presenting visual acuity (PVA) was measured indoor under ambient lighting with a LogMAR ETDRS tumbling E chart (Precision Vision, La Salle, Illinois, USA) per 
standardized protocol. Non-cycloplegic automated refraction was carried out for all participants at baseline and at the follow-up visit using the same device after proper calibration (KR-8800; Topcon Corp, Japan). Five consecutive measurements were performed for each eye with the mean recorded as the final value. At the 2014 followup, uncorrected VA was measured for all participants and subjective refraction was performed for participants with PVA $\leq 20 / 40$ to obtain their best-corrected visual acuity. Slit-lamp examination of the anterior segment was performed by an ophthalmologist throughout the study.

\subsection{Definitions}

Two definitions were used to define PVI and blindness. ${ }^{[20]}$ According to the WHO definition: PVI was defined as binocular PVA $<20 / 60$ to $20 / 400$ and presenting blindness was defined as binocular PVA <20/400. Definitions for PVI and blindness according to the United States (US) criteria were binocular PVA $<20 / 40$ to 20/200 and PVA $<20 / 200$, respectively. Based on these two criteria, incidence of PVI was calculated as the percentage of participants without PVI at baseline who developed PVI during the follow-up period. Similarly, incidence of presenting blindness was calculated as the percentage of participants without blindness at baseline who developed blindness during follow-up. Spectacle coverage for refractive error was assessed using the US definition, with "met need" defined as those with uncorrected binocular VA $<20 / 40$ who had spectacles that improved their VA to $\geq 20 / 40$. "Unmet need" was defined as those with uncorrected VA $<20 / 40$ but did not have spectacles or were under-corrected. Spectacle coverage rate was calculated by the following formula: spectacle coverage rate $=$ met need $/($ met need + unmet need $)$.

\subsection{Data Management and Analyses}


Spherical equivalent (SE), calculated as spherical power plus half of cylindrical power, was used to represent refraction. Baseline refractive state was categorized into myopia (SE < - 0.5D), emmetropia (-0.5D $\leq \mathrm{SE} \leq+0.5 \mathrm{D})$ and hyperopia (SE > 0.5D). Age was categorized into four groups: $35-44,45-54,55-64$ and $\geq 65$, based on the age obtained at baseline. Education level was dichotomized as less than high school and high school or above.

All statistical analyses were performed using STATA Statistical Software: Release 12.0 (StataCorp LP, Colleage Station, TX). Group t-test and trend-analysis were used to assess the difference in incidence of PVI in different groups by age, gender, education, refraction and baseline PVA. Multiple linear regression analysis was used to assess the association between incident PVI and potential risk factors. Chi-square test was used to assess the difference between spectacle coverage among different groups. P-values of $<0.05$ were considered statistically significant.

\section{RESULTS}

Of the 1817 baseline participants, 1427 (78.5\%) attended the follow-up examinations in 2014. Follow-up participants were significantly younger than non-participants, with a mean (standard deviation) age at baseline of 52.3 (11.6) years old and $54.9 \%$ were female. Detailed differences in characteristics between follow-up participants and nonparticipants have been reported previously. ${ }^{[21]}$

Based on the WHO and US definitions, the incidence of PVI in adults residing in urban China was $8.3 \%$ (95\%CI, 6.9 to 9.8 ) and $12.2 \%$ (95\%CI, 10.5 to 14.0 ), respectively (Table 1). Using the WHO definition, participants aged 65 years or older had 
significantly higher incidence compared with their younger counterparts ( $28.3 \%$ vs. 4.8\%; $P<0.001)$. Females $(P=0.003)$, participants with an education level of lower than high school $(P<0.001)$ and those with poorer PVA at baseline $(P<0.001)$ also had a higher PVI incidence. Emmetropic participants at baseline had a significantly lower incidence compared to myopic or hyperopic participants $(P<0.001)$. There were no incident blindness cases reported at the 2014 follow-up using the WHO criteria. However, when adopting the US definition, the incidence of presenting blindness was $0.14 \%$ ( $95 \% \mathrm{CI}, 0.00$ to 0.33 ).

Multiple regression analysis showed that older age $(P<0.001)$, female gender $(P=0.01)$ and worse PVA $(P<0.001)$ at baseline were associated with incident PVI. Participants with myopia at baseline were at higher odds of incident PVI compared to those with emmetropia $(P<0.001)$ (Table 2$)$. With the exception of female gender, all of the above associations remained after adopting the US definition. In addition, participants with hyperopia were at a higher risk of incident PVI than those with emmetropia using the US definition $(P=0.03)$.

Of the 327 participants with uncorrected VA<20/40 at the 2014 follow-up visit, only 139 had spectacles to achieve a PVA of $\geq 20 / 40$, resulting in an overall SCR of $42.5 \%$ (Table 3). Participants of older age and those with a lower level of education had a lower SCR (both with $\mathrm{P}<0.001$ ). Refractive status was also related to SCR, with an SCR of $56.6 \%$, $0.0 \%$ and $18.3 \%$ for myopes, emmetropes and hyperopes, respectively.

Table 4 shows the potential vision improvement with the best refractive correction at the 2014 follow-up visit. Of the 1427 participants, 1184 (83.0\%) had PVA of $\geq 20 / 40$ with their habitual spectacles. An improvement in VA of at least 2 lines could be 
achieved in $17.1 \%$ (203/1184) of participants. There were 186 participants (13.0\%) with VA correctable to $\geq 20 / 40$ but did not have any habitual correction. Of which, $91.4 \%$ could achieve a VA improvement of at least 2 lines and nearly $60 \%$ could achieve a VA improvement by at least 4 lines. In addition, for the 57 participants whose VA could not be improved to $\geq 20 / 40$, VA of 21 participants (36.9\%) could be improved by at least 2 lines from their PVA with spectacle correction.

\section{DISCUSSION}

This study documents the 6-year incidence and risk factors of PVI, as well as the SCR, of adults residing in urban Southern China. Strengths of the study include a large sample size, a high follow-up rate, a population-based design and the application of standardized method throughout the study. Results from our study offer important practical implications in planning for eye care services in urban China.

Presenting VA was utilized in the present study as it better reflects normal daily functional requirements compared to uncorrected or best-corrected VA. Comparisons between VI incidences should be made with caution in consideration of the difference in study population, design and definitions. Using the WHO criteria, incidence of PVI identified in our study $(8.33 \%, \geq 35$ years old) was higher than that reported in Melbourne $(1.38 \%, \geq 40$ years old $){ }^{[11]}$ Shahroud $(1.02 \%, 40-64 \text { years old })^{[12]}$ and Los Angeles $\left(1.8 \%, \geq 40\right.$ years old) ${ }^{[22]}$ but lower than that in Kenya $(11.9 \%, \geq 50$ years old). ${ }^{[23]}$ When compared with studies conducted in China, the Beijing Eye Study only reported incidence of best-corrected VI $(1.7 \%) .{ }^{[10]}$ The Liwan Eye Study, which is also based on an urban Southern Chinese population, reported a higher incidence of PVI compared with our study (WHO criteria, $12.4 \%$ vs. $8.33 \%$; US criteria, $20.6 \%$ vs. 
12.2\%). ${ }^{[13]}$ This could largely be attributed to that participants in the Liwan Eye study were relatively older (mean age: 63.4 years old), as the age-specific VI incidence using the US criteria for participants aged $50-59$ and $60-69$ in our study $(8.5 \%$ and $20.1 \%$, respectively) were higher than the corresponding figures in Liwan $(2.5 \%$ and $6.0 \%$, respectively).

In line with previous reports, ${ }^{[11]}$ age was the strongest risk factor for incident VI in the present study. Age-related eye diseases including cataract and age-related macular degeneration pose a higher risk of VI in the elderly. ${ }^{[24]}$ We also found that a lower education level and baseline refractive status were associated with incident PVI, which is consistent to previous studies. ${ }^{[13,25]}$ Females had a higher PVI incidence than males, and this difference became statistically significant when adopting the more stringent WHO criteria. It has been reported that females have less access to eye care services compared to males, ${ }^{[26]}$ and their higher tolerance of poor vision and worse financial situation could also lead to untreated eye diseases. ${ }^{[27]}$ This highlights an increased awareness of the importance of promoting eye care service for women.

It is widely acknowledged that refractive error is the leading cause of PVI and spectacles is the most efficient and cost-effective way to ease this burden, ${ }^{[10,13]}$ however SCR in urban China remains unsatisfactory. Based on our findings, the metneed SCR in urban Southern China (42.5\%) is much higher than that reported in rural areas including Niger ( $\geq 40$ years; 3.49\%) ${ }^{[28]}$ and Bangladesh ( $\geq 30$ years; $25.2 \%$ ), ${ }^{[29]}$ similar to Shanghai ( $\geq 60$ years, $44.12 \%)^{[15]}$ but much lower than Taiwan $(71.2 \%, \geq 65$ years) ${ }^{[14]}$ Tehran (66\%, $\geq 65$ years) and Australia (93.5\%, $\geq 40$ years) ${ }^{\left[{ }^{[3,31]}\right.}$ Besides the difference in ethnic background and age distributions examined, one may speculate that users' affordability and accessibility to eye care may explain the lower SCR in less- 
developed regions. In our study, younger participants were more likely to have a "metneed" refractive error correction. Older people might lack the awareness and demand for vision. Similarly, people with lower education level also had lower SCR, which may be partly explained by poor awareness and affordability to care.

It is not surprising that individuals with myopia had a higher SCR compared to their hypermetropic and emmoetropic counterparts, as they tend to experience blurred vision and commence spectacle wear earlier in life. However, the low coverage among the hyperopes should raise our attention as they may not realize the existence of vision problems and importance of addressing them. Given a current SCR of $42.5 \%$, increased efforts are required to develop an efficient strategy for providing low-cost refractive correction to the people in need, especially the higher risk populations identified above.

In addition to the SCR, we also investigated the potential VA improvement with best refractive correction compared to habitual spectacles. We report that $27.6 \%$ of the participants could achieve a VA improvement of at least 2 lines, and $8.3 \%$ by at least 4 lines with their best correction. This compares to $16.5 \%$ and $5.9 \%$, respectively, in Tehran. ${ }^{[30]}$ Furthermore, nearly half of the population did not achieve their optimal visual status with their habitual spectacles. These findings further highlight the need to strengthen health education and promote an annual refraction examination. Recently The New York Times has reported the challenge of uncorrected vision impairment and commented that spectacles is a simple way to improve a billion lives. With the growing aging population and increasing prevalence of refractive errors, how to improve SCR among the elderly would become an urgent issue in the near future. 
Potential limitations of our study should be noted. First, specific causes of PVI were not determined in this study. However as $96 \%$ of the study participants could achieve VA $\geq 20 / 40$ with best refractive correction, we regard under-corrected refractive error as the primary cause of PVI. ${ }^{[10,13]}$ Second, we only assessed the incidence of PVI, but not uncorrected and best-corrected VI. Despite this, PVA best reflects the real-world situation and aids future strategic planning. Lastly, SCR was calculated based on the 2014 follow-up participants instead of all baseline participants as subjective correction was not performed at baseline. Given that participants at the 2014 follow-up examinations were younger with better baseline VA, we suggest an even higher PVI incidence and lower SCR for the whole population-based cohort.

In conclusion, the incidence of PVI is high (WHO, 8.33\%; US, 12.2\%) in urban Southern China and is expected to increase with the aging society. The relatively low spectacle coverage and the unsatisfactory quality of optical correction could be a future health policy target. More efforts are needed to establish cost-effective strategies for promoting eye care services. 


\section{REFERENCES}

1. WHO. Visual impairment and blindness fact sheet. 2017. In. Visual impairment and blindness fact sheet. 2017.

2. Klein BE, Klein R, Lee KE, Cruickshanks KJ (1998) Performance-based and selfassessed measures of visual function as related to history of falls, hip fractures, and measured gait time. The Beaver Dam Eye Study. Ophthalmology; 105: 1604.

3. Weih LM, Hassell JB, Keeffe J (2002) Assessment of the impact of vision impairment. Invest Ophthalmol Vis Sci; 43: 927-35.

4. Zhang X, Bullard KM, Cotch MF, Wilson MR, Rovner BW et al. (2013) Association between depression and functional vision loss in persons 20 years of age or older in the United States, NHANES 2005-2008. JAMA ophthalmology; 131: 573-81.

5. Frick KD, Gower EW, Kempen JH, Wolff JL (2007) Economic impact of visual impairment and blindness in the United States. Archives of ophthalmology; 125: 544-50.

6. Stevens GA, White RA, Flaxman SR, Price H, Jonas JB et al. (2013) Global prevalence of vision impairment and blindness: magnitude and temporal trends, 1990-2010. Ophthalmology; 120: 2377-84.

7. Hsu WM, Cheng CY, Liu JH, Tsai SY, Chou P (2004) Prevalence and causes of visual impairment in an elderly Chinese population in Taiwan: the Shihpai Eye Study. Ophthalmology; 111: 62-9.

8. Huang S, Zheng Y, Foster PJ, Huang W, He M et al. (2009) Prevalence and causes of visual impairment in Chinese adults in urban southern China. Archives of ophthalmology; 127: 1362-7. 
9. Zhao J, Ellwein LB, Cui H, Ge J, Guan H et al. (2010) Prevalence of vision impairment in older adults in rural China: the China Nine-Province Survey. Ophthalmology; 117: 409-16, 16 e1.

10. You QS, Xu L, Yang H, Wang YX, Jonas JB (2011) Five-year incidence of visual impairment and blindness in adult Chinese the Beijing Eye Study. Ophthalmology; 118: $1069-75$.

11. Dimitrov PN, Mukesh BN, McCarty CA, Taylor HR (2003) Five-year incidence of bilateral cause-specific visual impairment in the Melbourne Visual Impairment Project. Investigative ophthalmology \& visual science; 44: 5075-81.

12. Hashemi H, Mehravaran S, Emamian MH, Fotouhi A (2017) Five-Year Incidence of Visual Impairment in Middle-Aged Iranians: The Shahroud Eye Cohort Study. Ophthalmic epidemiology; 24: 11-6.

13. Wang L, Huang W, He M, Zheng Y, Huang S et al. (2013) Causes and five-year incidence of blindness and visual impairment in urban Southern China: the Liwan Eye Study. Invest Ophthalmol Vis Sci; 54: 4117-21.

14. Kuang TM, Tsai SY, Hsu WM, Cheng CY, Liu JH et al. (2007) Correctable visual impairment in an elderly Chinese population in Taiwan: the Shihpai Eye Study. Investigative ophthalmology \& visual science; 48: 1032-7.

15. Zhu M, Tong X, Zhao R, He X, Zhao H et al. (2013) Visual impairment and spectacle coverage rate in Baoshan district, China: population-based study. BMC Public Health; 13: 311.

16. Bank TW. Statistic of Urban Population (\% of Total): The World Bank. In.Statistic of Urban Population (\% of Total): The World Bank, 2016.

17. Holden BA, Fricke TR, Wilson DA, Jong M, Naidoo KS et al. (2016) Global Prevalence of Myopia and High Myopia and Temporal Trends from 2000 through 2050. Ophthalmology. 
18. Congdon NG, Kong X, Meltzer ME, Chen Q, Zeng Y et al. (2012) Determinants and two-year change in anterior chamber angle width in a Chinese population. Ophthalmology; 119: 2500-6.

19. He $M$, Kong $X$, Chen $Q$, Zeng $Y$, Huang $Y$ et al. (2014) Two-year changes in refractive error and related biometric factors in an adult Chinese population. JAMA Ophthalmol; 132: 978-84.

20. WHO. International statistical classification of diseases and related health problems. In.International statistical classification of diseases and related health problems. World Health Organization, 2004.

21. Han X, Ellwein LB, Guo X, Hu Y, Yan W et al. (2017) Progression of Near Vision Loss and Incidence of Near Vision Impairment in an Adult Chinese Population. Ophthalmology; 124: 734-42.

22. Varma R, Chung J, Foong AW, Torres M, Choudhury F et al. (2010) Four-year incidence and progression of visual impairment in Latinos: the Los Angeles Latino Eye Study. American journal of ophthalmology; 149: 713-27.

23. Bastawrous A, Mathenge W, Wing K, Rono H, Gichangi M et al. (2016) Six-Year Incidence of Blindness and Visual Impairment in Kenya: The Nakuru Eye Disease Cohort Study. Investigative ophthalmology \& visual science; 57: 5974-83.

24. Weih LM, VanNewkirk MR, McCarty CA, Taylor HR (2000) Age-specific causes of bilateral visual impairment. Arch Ophthalmol; 118: 264-9.

25. Foran S, Rose K, Wang JJ, Mitchell P (2002) Correctable visual impairment in an older population: the blue mountains eye study. American journal of ophthalmology; 134: 712-9.

26. Lewallen S, Mousa A, Bassett K, Courtright P (2009) Cataract surgical coverage remains lower in women. The British journal of ophthalmology; 93: 295-8. 
27. Fenwick EK, Ong PG, Man REK, Sabanayagam C, Cheng CY et al. (2017) Vision impairment and major eye diseases reduce vision-specific emotional well-being in a Chinese population. $\mathrm{Br}$ J Ophthalmol; 101: 686-90.

28. Ezelum C, Razavi H, Sivasubramaniam S, Gilbert CE, Murthy GV et al. (2011) Refractive error in Nigerian adults: prevalence, type, and spectacle coverage. Invest Ophthalmol Vis Sci; 52: 5449-56.

29. Bourne RR, Dineen BP, Huq DM, Ali SM, Johnson GJ (2004) Correction of refractive error in the adult population of Bangladesh: meeting the unmet need. Investigative ophthalmology \& visual science; 45: 410-7.

30. Fotouhi A, Hashemi H, Raissi B, Mohammad K (2006) Uncorrected refractive errors and spectacle utilisation rate in Tehran: the unmet need. $\mathrm{Br} \mathrm{J}$ Ophthalmol; 90: 534-7.

31. Foreman J, Xie J, Keel S, Taylor HR, Dirani M (2017) Treatment coverage rates for refractive error in the National Eye Health survey. PloS one; 12: e0175353. 


\section{TABLES}

Table 1: Six-year incidence of presenting distance vision impairment

\begin{tabular}{|c|c|c|c|c|c|c|}
\hline \multirow[b]{2}{*}{ Characteristics } & \multicolumn{3}{|c|}{ WHO Criteria } & \multicolumn{3}{|c|}{ Unites States Criteria } \\
\hline & $\begin{array}{l}\text { No. at } \\
\text { risk }\end{array}$ & $\begin{array}{c}\text { Incidence \% } \\
\text { (95\% CI) }\end{array}$ & P-value & $\begin{array}{c}\text { No. at } \\
\text { risk }\end{array}$ & $\begin{array}{c}\text { Incidence \% } \\
(95 \% \mathrm{CI})\end{array}$ & P-value \\
\hline Age & & & $<0.001$ & & & $<0.001$ \\
\hline $35-44$ & 382 & $\begin{array}{c}4.45(2.37 \text { to } \\
6.53)\end{array}$ & & 374 & $\begin{array}{c}5.61(3.27 \text { to } \\
7.96)\end{array}$ & \\
\hline $45-54$ & 502 & $\begin{array}{c}2.39(1.05 \text { to } \\
3.73)\end{array}$ & & 491 & $\begin{array}{c}5.70(3.64 \text { to } \\
7.76)\end{array}$ & \\
\hline $55-64$ & 280 & $\begin{array}{c}9.64(6.16 \text { to } \\
13.1)\end{array}$ & & 272 & $\begin{array}{c}15.1(10.8 \text { to } \\
19.4)\end{array}$ & \\
\hline$\geq 65$ & 205 & $\begin{array}{c}28.3(22.1 \text { to } \\
34.5)\end{array}$ & & 180 & $\begin{array}{c}39.4(32.2 \text { to } \\
46.7)\end{array}$ & \\
\hline Sex & & & 0.003 & & & 0.011 \\
\hline Male & 627 & $\begin{array}{c}5.90(4.05 \text { to } \\
7.75)\end{array}$ & & 606 & $\begin{array}{c}9.74(7.37 \text { to } \\
12.1)\end{array}$ & \\
\hline Female & 742 & $\begin{array}{c}10.4(8.18 \text { to } \\
12.6)\end{array}$ & & 711 & $\begin{array}{c}14.3(11.8 \text { to } \\
16.9)\end{array}$ & \\
\hline Education & & & $<0.001$ & & & $<0.001$ \\
\hline $\begin{array}{c}\text { Less than high } \\
\text { school }\end{array}$ & 444 & $\begin{array}{c}15.1(11.7 \text { to } \\
18.4)\end{array}$ & & 417 & $\begin{array}{c}20.6(16.7 \text { to } \\
24.5)\end{array}$ & \\
\hline $\begin{array}{c}\text { High school or } \\
\text { above }\end{array}$ & 925 & $\begin{array}{c}5.08(3.67 \text { to } \\
6.50)\end{array}$ & & 900 & $\begin{array}{c}8.33(6.52 \\
\text { to } 10.1)\end{array}$ & \\
\hline Refraction & & & $<0.001$ & & & $<0.001$ \\
\hline Myopia & 390 & $\begin{array}{c}13.6(10.2 \text { to } \\
17.0)\end{array}$ & & 361 & $\begin{array}{c}18.0(14.0 \text { to } \\
22.0)\end{array}$ & \\
\hline Emmetropia & 580 & $\begin{array}{c}3.28(1.82 \text { to } \\
4.73)\end{array}$ & & 575 & $\begin{array}{c}5.04(3.25 \text { to } \\
6.84)\end{array}$ & \\
\hline Hyperopia & 399 & $\begin{array}{c}10.5(7.50 \text { to } \\
13.6)\end{array}$ & & 381 & $\begin{array}{c}17.6(13.7 \text { to } \\
21.4)\end{array}$ & \\
\hline Presenting VA & & & $<0.001$ & & & $<0.001$ \\
\hline $20 / 20$ & 803 & $\begin{array}{c}1.87(0.93 \text { to } \\
2.81)\end{array}$ & & 803 & $\begin{array}{c}3.74(2.42 \text { to } \\
5.05)\end{array}$ & \\
\hline $20 / 25$ & 295 & $\begin{array}{c}6.78(3.89 \text { to } \\
9.67)\end{array}$ & & 295 & $\begin{array}{c}14.9(10.8 \text { to } \\
19.0)\end{array}$ & \\
\hline $20 / 32$ & 149 & $\begin{array}{c}20.1(13.6 \text { to } \\
26.6)\end{array}$ & & 149 & $\begin{array}{c}34.9(27.2 \text { to } \\
42.6)\end{array}$ & \\
\hline $20 / 40$ & 70 & $\begin{array}{c}30.0(19.0 \text { to } \\
41.0)\end{array}$ & & 70 & $\begin{array}{c}50.0(38.0 \text { to } \\
62.0)\end{array}$ & \\
\hline $20 / 50$ & 52 & 53.8 (39.8 to & & - & - & \\
\hline
\end{tabular}

This article is protected by copyright. All rights reserved. 
67.9)

Total $\quad 1369 \quad 8.33(6.86$ to

9.79)

$1317 \quad 12.2(10.5$ to

WHO: world health organization; CI: confidence interval; VA: visual acuity.

This article is protected by copyright. All rights reserved. 
Table 2: Multiple regression of potential risk factors for incident presenting vision impairment

\begin{tabular}{lcccc}
\hline \multirow{2}{*}{ Factors } & \multicolumn{2}{c}{ WHO Criteria } & \multicolumn{2}{c}{ Unites States Criteria } \\
\cline { 2 - 5 } & Odds Ratio (95\% CI) & P Value & Odds Ratio (95\% CI) & P Value \\
\hline Age, y & $1.06(1.04$ to 1.08$)$ & $<0.001$ & $1.07(1.05$ to 1.09$)$ & $<0.001$ \\
Sex, female & $1.84(1.14$ to 2.96$)$ & 0.01 & $1.42(0.95$ to 2.10$)$ & 0.09 \\
$\begin{array}{l}\text { Education level, } \\
\text { high school or above }\end{array}$ & $0.63(0.39$ to 1.02$)$ & 0.06 & $0.66(0.44$ to 1.00$)$ & 0.05 \\
$\begin{array}{l}\text { Baseline SE } \\
\text { Myopia }\end{array}$ & 3.21(1.68 to 6.16) & $<0.001$ & $3.76(2.17$ to 6.52$)$ & $<0.001$ \\
$\quad$ Emmetropia & Reference & & Reference & \\
$\quad$ Hyperopia & $1.32(0.70$ to 2.48$)$ & 0.39 & $1.79(1.07$ to 3.00$)$ & 0.03 \\
Presenting distance VA & $0.01(0.003$ to 0.04$)$ & $<0.001$ & $0.02(0.01$ to 0.06$)$ & $<0.001$ \\
\hline
\end{tabular}

CI: confidence interval; VA: visual acuity.

Table 3: Spectacle coverage for refractive errors at 2014 follow-up examination

\begin{tabular}{|c|c|c|c|c|c|}
\hline Characteristic & $\begin{array}{c}\text { Total } \\
\text { number }\end{array}$ & $\begin{array}{l}\text { Met } \\
\text { Need } \\
\text { (n) }\end{array}$ & $\begin{array}{c}\text { Unmet } \\
\text { Need (n) }\end{array}$ & $\begin{array}{c}\text { Correction } \\
\text { Coverage } \\
(\%)\end{array}$ & P value \\
\hline Age at Baseline & & & & & $<0.001$ \\
\hline $35-44$ & 109 & 71 & 38 & 65.1 & \\
\hline $45-54$ & 76 & 36 & 40 & 47.4 & \\
\hline $55-64$ & 71 & 23 & 48 & 32.4 & \\
\hline$\geq 65$ & 71 & 9 & 62 & 12.7 & \\
\hline Sex & & & & & 0.07 \\
\hline Male & 139 & 67 & 72 & 48.2 & \\
\hline Female & 188 & 72 & 116 & 38.3 & \\
\hline Education & & & & & $<0.001$ \\
\hline Less than high school & 99 & 15 & 84 & 15.2 & \\
\hline High school or above & 228 & 124 & 104 & 54.4 & \\
\hline $\begin{array}{c}\text { Baseline refractive } \\
\text { state }\end{array}$ & & & & & $<0.001$ \\
\hline Myopia & 219 & 124 & 95 & 56.6 & \\
\hline Emmetropia & 26 & 0 & 26 & 0.00 & \\
\hline Hyperopia & 82 & 15 & 67 & 18.3 & \\
\hline
\end{tabular}

This article is protected by copyright. All rights reserved. 
Table 4: Lines of improvement with best correction at the 2014 follow-up

\begin{tabular}{cccccccc}
\hline Category & Total & \multicolumn{7}{c}{ Lines of improvement possible with best correction } \\
\cline { 3 - 8 } & No. & $\mathbf{0}$ & $\mathbf{1}$ & $\mathbf{2}$ & $\mathbf{3}$ & $\mathbf{4}$ & $\mathbf{2}$ \\
\hline Already corrected to & \multirow{2}{*}{1184} & 813 & 168 & 141 & 62 & - & - \\
$\mathbf{2 0 / 4 0}$ & & $(68.7)$ & $(14.2)$ & $(11.9)$ & $(5.24)$ & & \\
Correctable to & \multirow{2}{*}{186} & - & 16 & 24 & 33 & 53 & 60 \\
$\mathbf{2} \mathbf{2 0 / 4 0}$ & & & $(8.60)$ & $(12.9)$ & $(17.7)$ & $(28.5)$ & $(32.3)$ \\
Not Correctable to & \multirow{2}{*}{57} & $(26.3)$ & $(36.8)$ & $(22.8)$ & $(5.26)$ & $(3.51)$ & $(5.26)$ \\
$\mathbf{2} \mathbf{2 0 / 4 0}$ & & 828 & 205 & 178 & 98 & 55 & 63 \\
Total & \multirow{2}{*}{1427} & $(58.0)$ & $(14.4)$ & $(12.5)$ & $(6.87)$ & $(3.85)$ & $(4.41)$ \\
\hline
\end{tabular}

Data expressed as No. (\%). 


\section{University Library}

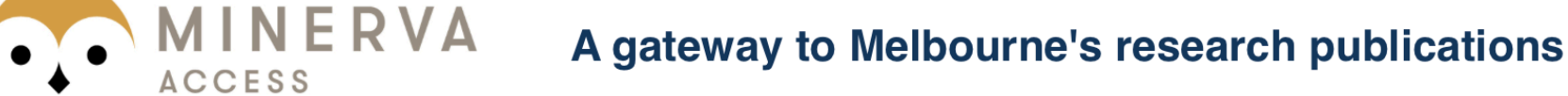

Minerva Access is the Institutional Repository of The University of Melbourne

\section{Author/s:}

Han, X;Liao, C;Liu, C;Lee, PY;Zhang, J;Keel, S;He, M

Title:

Incidence and correction of vision impairment among elderly population in southern urban China

Date:

2019-05-01

\section{Citation:}

Han, X., Liao, C., Liu, C., Lee, P. Y., Zhang, J., Keel, S. \& He, M. (2019). Incidence and correction of vision impairment among elderly population in southern urban China. CLINICAL AND EXPERIMENTAL OPHTHALMOLOGY, 47 (4), pp.439-444. https:// doi.org/10.1111/ceo.13431.

Persistent Link:

http://hdl.handle.net/11343/284686 